\title{
Optimization of Extraction Induced by Emulsion Breaking Variables for Subsequent Determination of Crude Oil Salinity by lon Chromatography
}

\author{
Anna Carolina de Oliveira Pinheiro Ramos ${ }^{a}$, Gabriel Rocha Figueira Caldeira ${ }^{a}$, Carolina Ramos \\ de Oliveira Nunes ${ }^{b}$, Wagner da Silva Terrac, Murilo de Oliveira Souza ${ }^{\text {a* }}$ (iD \\ aLaboratório de Análises Químicas e Agroambientais (LAQUA). Instituto Federal de Educação, Ciência e Tecnologia \\ Fluminense, Campus Itaperuna, BR 356, km 3, 28300-000, Itaperuna, Rio de Janeiro, Brazil

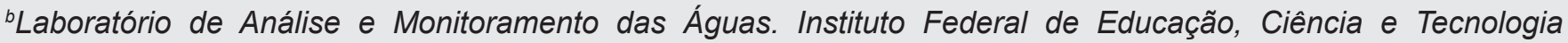 \\ Fluminense, Polo de Inovação, 28100-000, Campos dos Goytacazes, Rio de Janeiro, Brazil \\ 'Laboratório de Petróleo. Instituto Federal de Educação, Ciência e Tecnologia Fluminense, Campus Campos \\ Centro, 28030-130, Campos dos Goytacazes, Rio de Janeiro, Brazil
}

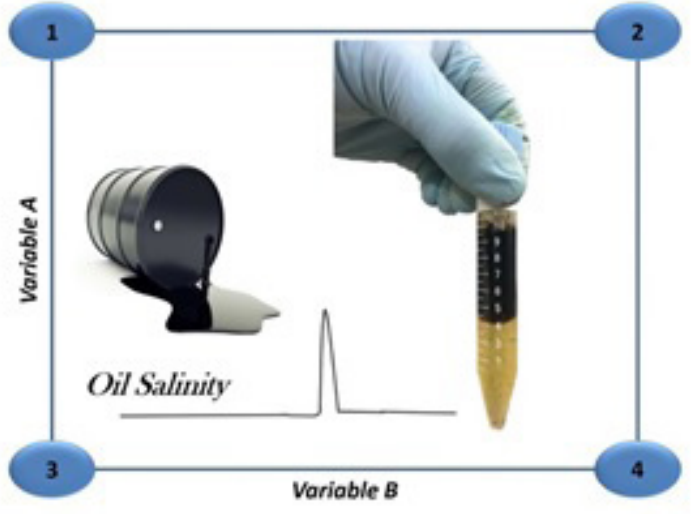

Due to natural geological oil formation and exploration processes, high amounts of saltwater are emulsified in oil, resulting in high salinity in oil extraction wells. This salinity is due to the presence of non-metals of forming inorganic salt, such as chloride, which, when subjected to high temperatures, tend to react with water vapor to form hydrochloric acid, causing distillation tower corrosion. In this context, extraction induced by emulsion breaking (EIEB) has been as an alternative procedure to the official ASTM D6470 method for chloride extraction and subsequent determination by ion chromatography in oil samples. Thus, the experimental EIEB variables of $\mathrm{HNO}_{3}$ volume $(\mathrm{V})$ and Triton X-114 mass $(T)$ were optimized using a $2^{2}$ factorial design with three central points. The optimal condition obtained for the EIEB and chloride determination was $V=500 \mu \mathrm{L}$ and $\mathrm{T}=0.5000 \mathrm{~g}$. The developed procedure allowed for the assessment of samples presenting different ${ }^{\circ} \mathrm{API}$ (22.9 to 28.8), which originated from the post-salt. Besides, limits of detection of $0.3-0.4 \mathrm{mg} \mathrm{kg}^{-1}$ chloride were achieved. The accuracy of the procedure was confirmed by addition/ recovery tests $(100.4-100.7 \%)$.

Keywords: Chloride, Ion Chromatography, EIEB, Factorial Design, Corrosion, Refining

\section{INTRODUCTION}

Oil is a highly complex mixture consisting of saturated hydrocarbons, aromatics, and polycyclic compounds (resins and asphaltenes), as well as small amounts of organic compounds containing sulfur,

Cite: Ramos, A. C. O. P.; Caldeira, G. R. F.; Nunes, C. R. O.; Terra, W. S.; Souza, M. O. Optimization of Extraction Induced by Emulsion Breaking Variables for Subsequent Determination of Crude Oil Salinity by lon Chromatography. Braz. J. Anal. Chem., 2020, 7 (27), pp 31-39. doi: http://dx.doi.org/10.30744/brjac.2179-3425.AR-15-2020

Received 24 April 2020, Revised 15 June 2020, Accepted 24 June 2020, Available online 30 June 2020. 
nitrogen, oxygen and even lower amounts of metal compounds, particularly vanadium, nickel, iron, and copper [1-3]. Its chemical composition may vary from one specific site to another, according to regional and local variations, and the physicochemical processes that occur during its geological origin, thus leading to a wide variety of samples presenting different physicochemical properties $[4,5]$. Due to this, the determination of certain physicochemical characterization parameters such as density, viscosity, salinity, basic sediment and water contents (BSW); saturated, aromatics, resins and asphaltenes content (SARA), among others, is required to order to propose crude oil transportation and refining strategies [6-8].

Particular emphasis is given to salinity, as high amounts of saltwater are emulsified to the oil through natural oil geological formation processes and exploration and production processes, leading to high salinity values in oil extraction wells [3,9]. This salinity is due to the presence of non-metals that form inorganic salts, with chloride as the main salt-forming anion [9]. In parallel, salts contained in the oil, when subjected to high temperatures, tend to react with water vapor to form hydrochloric acid and, consequently, cause corrosion in oil distillation towers $[9,10]$. Thus, oil salinity determination should be performed to avoid potential problems during oil distillation and other oil production stages [11].

For the extraction of water in oil, there are several physical techniques, such as gravity or ultrasonic separation, skimming, absorption and filtration [12]. Extraction induced by emulsion breaking (EIEB) can be used for the extraction of emulsified saltwater in oil (aqueous extract), enabling the determination of chloride salts present in this extract. EIEB consists in the formation of oil-in-water emulsions by intense sample agitation (in this case, oil) mixed with an acidified surfactant. After heating, the emulsion ruptures, resulting in an organic phase containing the organic oil fraction and an acidified aqueous phase, the lower portion containing inorganic salts, termed the aqueous extract [13]. EIEB can be an advantageous proposition and an alternative method for the determination of oil chloride salts (salinity). Also, this method presents lower costs and is cleaner, due to the use of smaller sample volumes and organic solvents than the recommended oil salinity determination procedures (ASTM D 6470 [14] and ASTM D 3230 [15]). Besides that, chloride results after EIEB did not differ statistically from those obtained by the most commonly applied official method for the determination of this element in crude oil (ASTM D6470) [16].

Robaina et al. [16] applied the EIEB procedure to transfer the chloride to the aqueous oil phase during the emulsion breaking of oil samples. Chloride determination in the extracts was performed by ion chromatography (IC) using a conductivity detector. Several parameters were evaluated, such as the relation among the oil phase and aqueous phase, crude oil and mineral oil ratio, shaking time, type, and concentration of surfactant that could affect the performance of the method. However, no multivariate statistical procedure was used to evaluate the EIEB variables that could affect the chloride extraction to the aqueous phase and its determination by ion chromatography. Besides that, for extraction of chloride from samples was used mineral oil to solubilize the crude oil. Trevelin et al. [13] developed an analytical procedure for the determination of $\mathrm{Ba}, \mathrm{Ca}, \mathrm{Mg}$, and $\mathrm{Na}$ in heavy oil samples after EIEB. Metal recovery percentages ranged from $99 \%$ to $104 \%$ and $\mathrm{Ba}$ and $\mathrm{Na}$ determination results showed good agreement with certified reference material (NIST 1634c) values.

In this context, the present study aimed to evaluate the use of a $2^{2}$ factorial design with three central points to optimizer the variables of extraction induced by emulsion breaking (EIEB) for chloride extraction and subsequent determination by ion chromatography in oil samples. In addition, it is noteworthy that the EIEB was used to extract chloride from four oil samples in order to assess whether studied samples presented salinity exceeding the maximum permissible concentration for oil production refining and processing steps.

\section{MATERIALS AND METHODS \\ Instrumentation}

An ion chromatograph (883 Basic IC Plus, Metrohm, Switzerland) coupled to an autosampler (863 Compact Autosampler, Metrohm, Switzerland) was used for chloride determinations. The calibration curves ranged from 0.1 to 10.0 and 1.00 to $60.00 \mathrm{mg} \mathrm{L}^{-1}$ chloride. Conductivity signals were measured with a heated 
DSP conductivity cell and chromatograms were acquired using the MagIC Net 3.1 software. Chloride ion separation was carried out using an analytical column (Metrosep A Supp 5, Metrohm, Switzerland), 150 $\mathrm{mm}$ in length with $5.0 \mu \mathrm{m}$ particle size. A pre-column (Metrosep A Supp 5 Guard, Metrohm, Switzerland), $10 \mathrm{~mm}$ in length with $5.0 \mu \mathrm{m}$ particle size, was used to protect the analytical column. A total of $20 \mu \mathrm{L}$ were injected for all analyses. The parameters used to perform the analyses are listed in Table I.

Table I. Ion chromatograph operating conditions

\begin{tabular}{lc}
\hline Pressure $(\mathrm{MPa})$ & 10 \\
Column temperature $\left({ }^{\circ} \mathrm{C}\right)$ & $25 \pm 3$ \\
Injected volume $(\mu \mathrm{L})$ & 20 \\
Time $(\mathrm{min})$ & 18 \\
\hline
\end{tabular}

A mix stirrer (Phoenix, model AP 56), a heating plate (Centauro, CAMA-10), and a centrifuge (Edulab, model 80-2B) were used for the EIEB process.

\section{Samples}

Different oil samples (S1, S2, S3, and S4) were used, generating aqueous extracts E1, E2, E3, and E4, respectively. All samples were obtained from the Campos dos Goytacazes Basin, in the state of Rio de Janeiro, provided by the Petrobras S.A. Fluid Laboratory, located at the Imbetiba base in the city of Macaé, Rio de Janeiro. Table II presents performed physicochemical characterizations. The physical-chemical characterization parameters were carried out according to the procedure developed by Terra, Martins and, da Cruz (2019) [6].

Table II. Physical and chemical parameters determined in oil samples

\begin{tabular}{|c|c|c|c|c|c|}
\hline Samples & $\rho_{24.2^{\circ} \mathrm{C}}\left(\mathrm{g} \mathrm{cm}^{-3}\right)^{\mathrm{a}}$ & ${ }^{\circ} \mathrm{API}_{24.2{ }^{\circ} \mathrm{C}}{ }^{\mathrm{b}}$ & ${ }^{\circ} \mathrm{API}{ }_{15.6{ }^{\circ} \mathrm{C}}{ }^{\mathrm{b}}$ & $\mu(\mathrm{mPa} \mathrm{s})^{\mathrm{c}}$ & $\operatorname{BSW}\left(\% v v^{-1}\right)^{d}$ \\
\hline S1 & $0.8825 \pm 0.0002$ & 28.8 & $27.6 \pm 0.1$ & $53.3 \pm 0.5$ & 0.35 \\
\hline S2 & $0.8905 \pm 0.0002$ & 27.4 & $26.0 \pm 0.1$ & $34.8 \pm 0.3$ & 0.25 \\
\hline S3 & $0.9165 \pm 0.0002$ & 22.9 & $21.6 \pm 0.1$ & $127 \pm 1$ & 0.10 \\
\hline S4 & $0.9115 \pm 0.0002$ & 23.7 & $22.5 \pm 0.1$ & $304 \pm 2$ & 0.10 \\
\hline
\end{tabular}

${ }^{\mathrm{a}} \rho_{24.2^{\circ} \mathrm{C}}$ specific oil mass in $\mathrm{g} \mathrm{cm}^{-3}$, obtained at room temperature $\left(24.2^{\circ} \mathrm{C}\right) ;{ }^{\circ} \mathrm{API}\left(\right.$ American Oil Institute); ${ }^{\mathrm{c}} \mu$ absolute viscosity determined in a timely and direct manner at room temperature of $24.2{ }^{\circ} \mathrm{C} ;{ }^{\mathrm{d}} \mathrm{BSW}$ (Basic Sediment and Water).

\section{Material and reagents}

Ultrapure water (resistivity $=18.2 \mathrm{M} \Omega \mathrm{cm}$ ) was prepared using a reverse osmosis system with ultraviolet disinfection (OS20LXE, Gehaka, Brazil). Chloride ion standard solutions were prepared by diluting a 1000 $\mathrm{mg} \mathrm{L}^{-1}$ standard bromide, chloride, nitrate, sulfate, fluoride, and phosphate solution (SpecSol, Sao Paulo, Brazil) with ultrapure water.

Nitric acid $68 \% \mathrm{~m} \mathrm{~m}^{-1}$ P.A. (Vetec, Rio de Janeiro, Brazil), sulfuric acid $98 \% \mathrm{~m} \mathrm{~m}^{-1}$ P.A. (Dynamics, Sao Paulo, Brazil), sodium carbonate P.A. (Dynamics, Sao Paulo, Brazil), sodium P.A. (Dynamics, Sao Paulo, Brazil), sodium bicarbonate P.A. (Dynamics, São Paulo, Brazil) and Triton X-114 (Nuclear, Sao Paulo, Brazil) were used. Polypropylene tubes (Techno Plastic Products AG, Transadingen, Switzerland) (15.0 $\mathrm{mL}$ capacity) were used for the EIEB assessments. 


\section{Oil salinity determination}

A mass of $3.0000 \pm 0.0001 \mathrm{~g}$ of each sample was weighed directly into $15.0 \mathrm{~mL}$ polyethylene tubes. Then, $500 \mu \mathrm{L}$ of concentrated $\mathrm{HNO}_{3}$ and $0.5000 \mathrm{~g}$ of Triton X-114 (optimal conditions) were added to each polyethylene tube - Figure 1(a), which was then made up to $10 \mathrm{~mL}$ with deionized water. Subsequently, the tubes were shaken vigorously for 15 minutes using a mix stirrer to form oil/water emulsions. Breaking of the formed oil/water emulsions was achieved by heating for 15 minutes at $80{ }^{\circ} \mathrm{C}$ using a water bath. The tubes were then centrifuged for 5 minutes at 3,000 rpm forming two phases, one aqueous containing the extracted chloride and one containing the organic oil portion - Figure 1(b). Finally, a thin-tipped pipette was used; inserting it through the organic phase of oil into the aqueous phase, where the entire aqueous phase formed was removed and weighed. The organic phase was discarded.
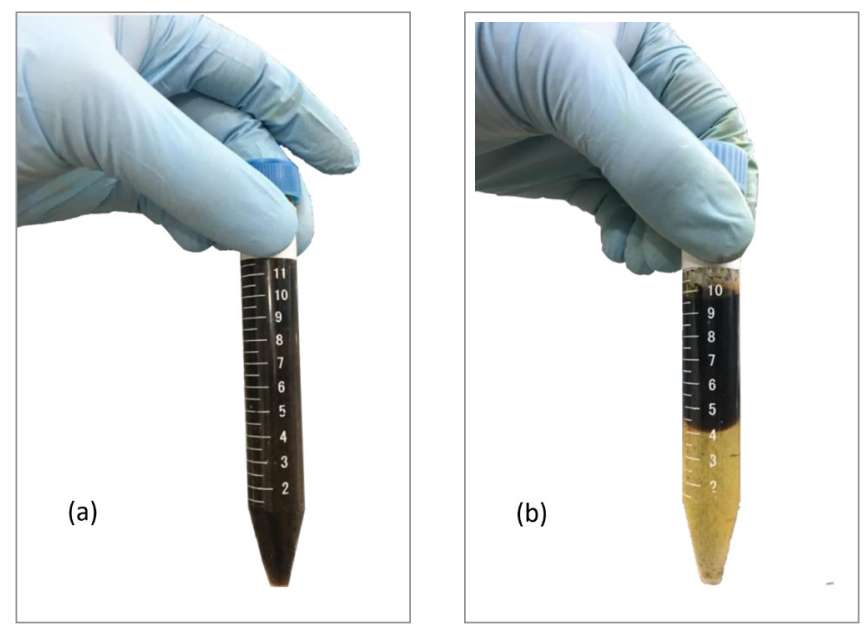

Figure 1. (a) Oil/water emulsion and (b) emulsion breaking (organic phase and aqueous extract E1).

Subsequently, the aqueous extracts were filtered through $0.45 \mu \mathrm{m}$ cellulose acetate membranes (Filtrilo, Brazil) and diluted 10 times before being injected into the ion chromatography for chloride determination. Oil salinity was reported as $\mathrm{mg} \mathrm{kg}^{-1} \mathrm{NaCl}$. Preparation blanks of each sample were also analyzed to assess the presence of chloride in water or reagents.

Due to the absence of certified material for oil extract samples, procedure accuracy was verified by chloride addition/recovery tests prior to EIEB. Concerning the recovery tests, a sodium chloride mass (before EIEB) was added to the S1 oil sample to obtain a final concentration of $833 \mathrm{mg} \mathrm{kg}^{-1} \mathrm{NaCl}$. Addition/ recovery tests aided to ensure the efficiency of the proposed procedure.

\section{Chromatographic conditions}

An isocratic method (3.2 mmol L-1 $\mathrm{Na}_{2} \mathrm{CO}_{3}$ and $1.0 \mathrm{mmol} \mathrm{L}^{-1} \mathrm{NaHCO}_{3}$ ) at a flow rate of $0.7 \mathrm{~mL} \mathrm{~min}^{-1}$ was used for chloride separation during the injection stages of the standards for 18 minutes. The chloride peak appeared at $5.610 \pm 0.020 \mathrm{~min}$ (Figure 2). Sulfuric acid at $0.100 \mathrm{~mol} \mathrm{~L}^{-1}$ was used as a suppressor. Between the injection of each sample, a blank consisting of ultrapure water was injected to clean the column. All aqueous extract (E1 - E4) analyzes were performed in duplicates. 


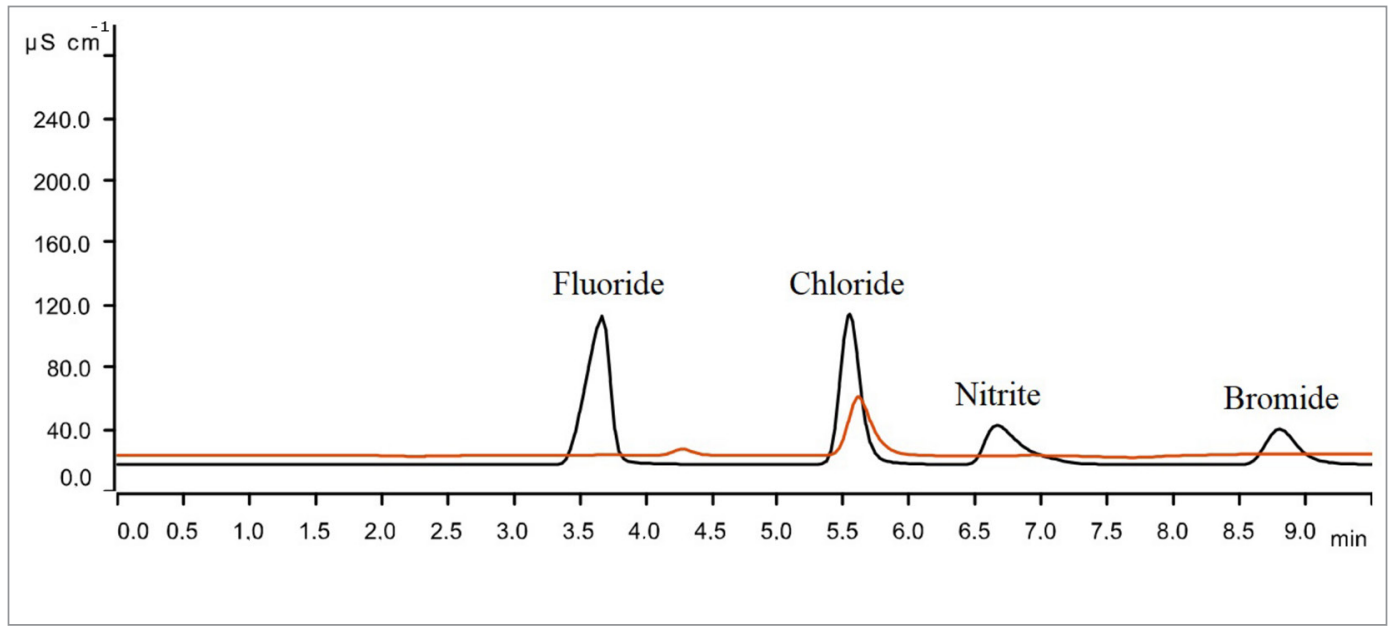

Figure 2. Typical chromatograms of the aqueous extract (E1) diluted 1:10 (red line) and a $60.0 \mathrm{mg} \mathrm{L}^{-1}$ chloride standard solution (black line).

\section{EIEB Variable Optimization}

A $2^{2}$ factorial design with three central points was employed to evaluate the two EIEB variables of the emulsion - breaking extraction procedure: $\mathrm{HNO}_{3}(\mathrm{~V})$ volume and Triton X-114 (T) surfactant mass. A total of seven trials $\left(2^{k}, k\right.$ being the number of variables studied in the full factorial design, in this case, $2^{2}=4$; plus three trials at the central point) were performed. The entire optimizing process was performed using Microsoft Excel ${ }^{\circledR} 2010$ software.

\section{RESULTS AND DISCUSSION \\ Optimal EIEB conditions}

In order to establish the best conditions for chloride extraction from the aqueous oil phase, a $2^{2}$ factorial design with three central points was employed, evaluating two EIEB variables: $\mathrm{HNO}_{3}(\mathrm{~V})$ volume and Triton $\mathrm{X}-114(\mathrm{~T})$ mass. To avoid biased results the experiments were performed randomly. Table III presents the two variables $(V$ and $T)$ and the three studied levels $(-1,0,1)$. All factorial design step was performed with oil sample S1.

Table III. Variables and levels assessed in the $2^{2}$ Factorial Design with three central points

\begin{tabular}{|c|c|c|c|c|c|}
\hline \multirow{2}{*}{$\begin{array}{l}\text { Experiment } \\
\text { (sample S1) }\end{array}$} & \multicolumn{2}{|c|}{ Variables } & \multirow[b]{2}{*}{ Oil mass $(g)^{b}$} & \multirow[b]{2}{*}{$\begin{array}{l}\text { Aqueous extract } \\
\text { mass }(g)(E 1)^{c}\end{array}$} & \multirow[b]{2}{*}{$\begin{array}{l}\text { Response } \\
\left(\mathrm{mg} \mathrm{kg}^{-1}\right)^{\mathrm{c}}\end{array}$} \\
\hline & $\begin{array}{l}\mathrm{HNO}_{3} \text { volume } \\
(\mu \mathrm{L})(\mathrm{V})^{\mathrm{a}}\end{array}$ & $\begin{array}{l}\text { Triton } X-114 \\
\text { mass }(g)(T)^{a}\end{array}$ & & & \\
\hline 1 & $500(-1)$ & $0.1225(-1)$ & 3.0253 & 5.9504 & 602.4 \\
\hline 2 & $1500(1)$ & $0.1274(-1)$ & 3.0127 & 6.3159 & 461.7 \\
\hline 3 & $500(-1)$ & $0.9125(1)$ & 3.1534 & 4.2130 & 478.0 \\
\hline 4 & $1500(1)$ & $0.8901(1)$ & 2.9987 & 5.1196 & 369.4 \\
\hline 5 & $1000(0)$ & $0.5362(0)$ & 3.0153 & 5.1049 & 506.9 \\
\hline 6 & $1000(0)$ & $0.5130(0)$ & 2.9555 & 5.0055 & 513.1 \\
\hline 7 & $1000(0)$ & $0.5326(0)$ & 2.9426 & 4.9038 & 493.3 \\
\hline
\end{tabular}

aValues within the parentheses indicate the assessed levels; ' Oil mass (S1) used in each experiment; 'aqueous extract mass (E1) obtained after each EIEB. ${ }^{d}$ chloride concentration determined in the aqueous extract (E1), expressed as reported in $\mathrm{mg} \mathrm{kg}^{-1}$ oil (S1). 
All effects and their experimental errors were then calculated from the responses generated in the complete $2^{2}$ factorial design with three central points. Significant effects were analyzed at $95 \%$ confidence by replication at the center point and the $t$-test with 2 degrees of freedom ( $t$ student $=4.303$ ). The significance of each effect was calculated from the multiplication of $t$ student's value of 4.303 by the estimate of the standard error of the effect $[5,17]$. Figure 3 presents the significant effects of the assessed variables for chloride determination by ion chromatography for sample S1.

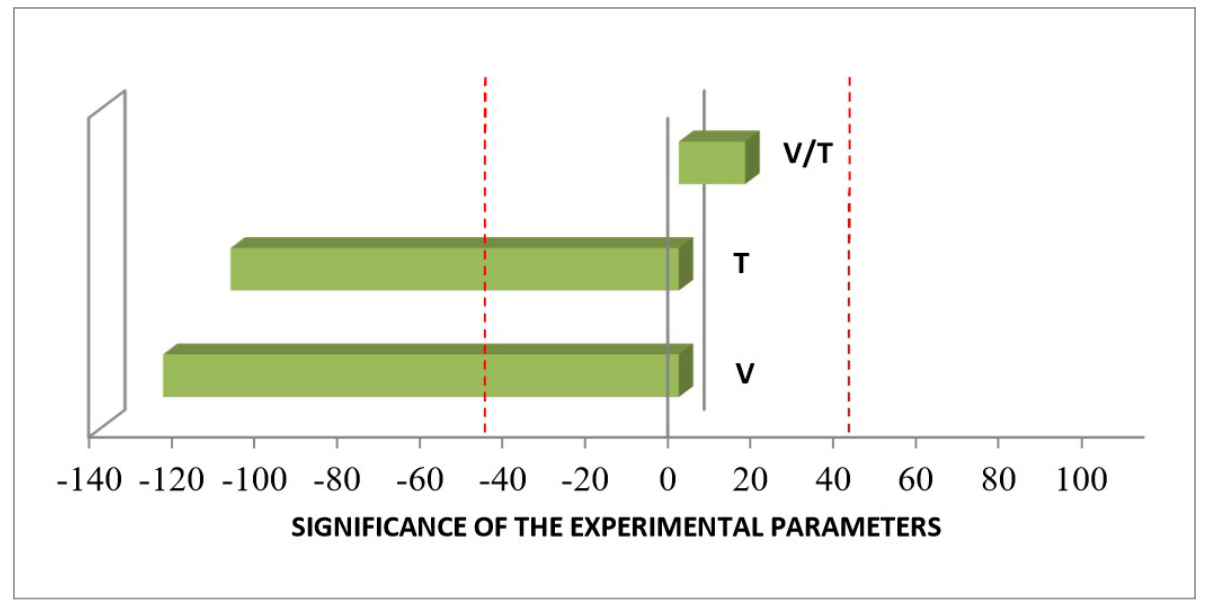

Figure 3. Graphical representation of the significance of the assessed variables: $\mathrm{V}\left(\mathrm{HNO}_{3}\right.$ volume), $\mathrm{T}$ (Triton $\mathrm{X}-114$ mass), and $\mathrm{V} / \mathrm{T}$ (their interactions) for chloride determination in sample S1 ( $t$ student's value $\mathrm{x}$ standard error estimate $= \pm 43.6$ ).

Variables $\mathrm{V}$ and $\mathrm{T}$ are significant for oil chloride extraction into the aqueous phase. Triton $\mathrm{X}-114$ (T) is a surfactant used to reduce the surface and interfacial tensions of the medium and facilitate emulsion formation $[13,18]$. During emulsion formation, the two immiscible liquids (oil/water) are mixed under constant agitation, forming even droplets of one liquid inside the other $[19,20]$. This oil/water interaction allows inorganic chloride to come into contact with water droplets. During emulsion breaking, these droplets tend to stick together and the liquids separate again, allowing for the chloride to migrate to the aqueous phase. According to Figure 3, better results for chloride extraction would occur with lower Triton X-114 masses, that is, the increase in surfactant concentration decreased the extraction efficiency. Trevelin et al. [13] obtained a maximum extraction for the $\mathrm{Ba}, \mathrm{Ca}, \mathrm{Mg}$, and $\mathrm{Na}$ elements when the surfactant was used at $5 \% \mathrm{~m} \mathrm{v}^{-1}$ and observed a reduction in the extraction of these elements when were used lower Triton X-114 masses. Robaina et al. [16] used $2.5 \% \mathrm{~m} \mathrm{v}^{-1}$ of Triton X-114 to the maximum extract of chloride in 0.5000

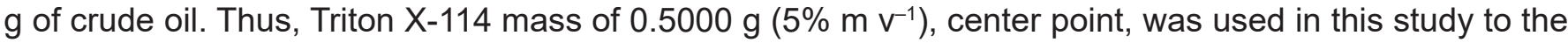
maximum extract of chloride in $3.0000 \mathrm{~g}$ of crude oil, since a mass less than $0.5000 \mathrm{~g}$ of this surfactant can make it difficult to form the emulsion (due to the greater mass of crude oil used). In addition, as the V/T interaction was not significant, it is possible to optimize each variable independently and, therefore, only $\mathrm{V}\left(\mathrm{HNO}_{3}\right.$ volume) was optimized, as it has a more significant effect during EIEB. The variable $\mathrm{V}\left(\mathrm{HNO}_{3}\right.$ volume) was significant for chloride extraction from the oil sample. In addition, the $2^{2}$ factorial design with three central points indicates that the $\mathrm{HNO}_{3}$ volume should be decreased to obtain an optimal chloride extraction condition (Figure 3). In this sense, a univariate evaluation was performed, varying $\mathrm{HNO}_{3}$ volume at five levels $(700,500,300,100$, and $0 \mu \mathrm{L})$, to obtain the ideal volume of this acid for the EIEB (Figure 4). 


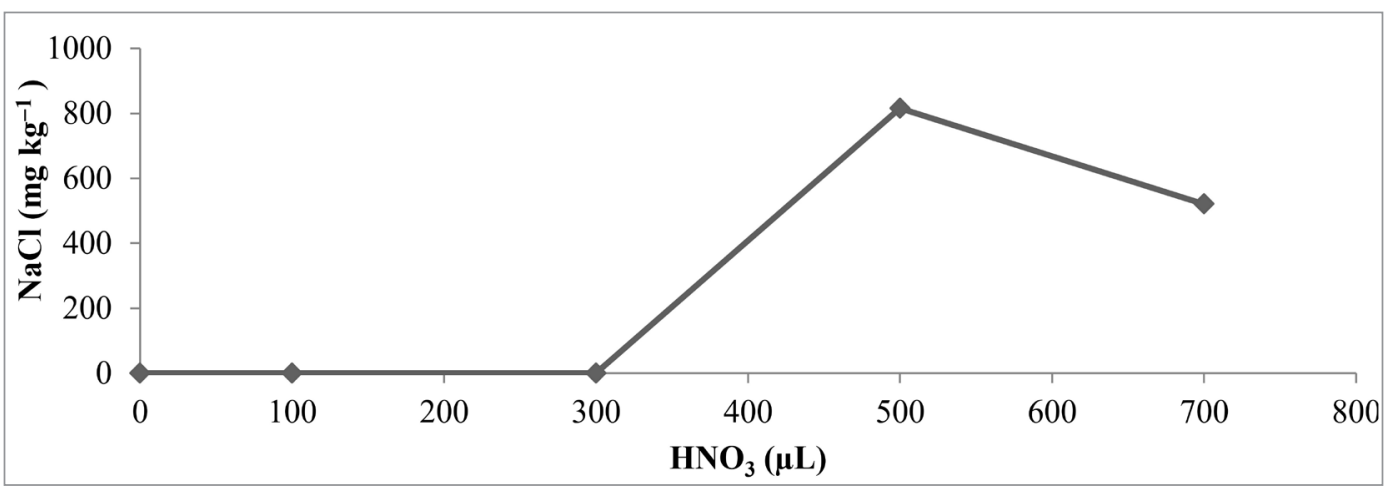

Figure 4. Variation of the extracted chloride to the aqueous phase in relation to the volume of nitric acid used in the extraction for sample S1.

Nitric acid aids in chloride extraction and provides greater stabilization of inorganic species in aqueous media, so that the analyte (chloride) does not precipitate and is not adsorbed to the vial walls [13]. EIEB only occurred at $\mathrm{HNO}_{3}$ volumes of 500 and $700 \mu \mathrm{L}$. The use of the other volumes $(300,100$, and $0 \mu \mathrm{L}$ of $\mathrm{HNO}_{3}$ ) did not result in phase separation, indicating that the presence of this acid is important for EIBE. Besides, decreased chloride extraction was observed when using $700 \mu \mathrm{L}$ of $\mathrm{HNO}_{3}$, indicating that a volume of over $500 \mu \mathrm{L}$ is not required for chloride extraction. The high acidity resulting from $\mathrm{HNO}_{3}$ may increase conductivity during chloride determination by ion chromatography, causing problems during this analysis. Therefore, although a high concentration of $\mathrm{HNO}_{3}$ may aid chloride extraction, it may also impair its determination during ion chromatography analyses. Thus, $V=500 \mu \mathrm{L}$ and $\mathrm{T}=0.5000 \mathrm{~g}$ were used for the EIEB process applied to samples S1 - S4 to establish an ideal condition for chloride extraction and determination.

\section{Oil salinity determination}

After optimizing the optimum EIEB condition, chloride concentrations in the S1 - S4 oil samples were determined through chloride determinations in the aqueous extracts (E1 - E4). As chloride concentrations in aqueous extracts from S2, S3 and S4 were much lower than S1, two optimal working ranges (OWR) were obtained for chloride determination by ion chromatography, one with higher chloride concentrations and one with lower chloride concentrations. Table IV presents the performance characteristics of the procedure developed under the optimized extraction condition.

Table IV. Performance characteristics achieved after emulsion breaking induced extraction

\begin{tabular}{lccccccc}
\hline Samples & $\begin{array}{c}\text { OWR } \\
\left.(\mathbf{m g ~ L})^{-1}\right)\end{array}$ & Linearity $(\mathbf{r})$ & Sensitivity & $\begin{array}{c}\text { LOD } \\
\left(\mathbf{m g ~ k g}^{-1}\right)^{\mathbf{b}}\end{array}$ & $\begin{array}{c}\text { LOQ } \\
\left(\mathbf{m g ~ k g}^{-1}\right)^{\mathbf{c}}\end{array}$ & $\begin{array}{c}\text { Conc } \\
\left(\mathbf{m g ~ k g}^{-1}\right)^{\mathbf{d}}\end{array}$ & Rec \% \\
\hline S1 & $1.0-60.0$ & 0.995 & 0.296 & 0.3 & 1.0 & $829.9 \pm 2.9$ & 100.4 \\
S1 rep & & & & & & $827.2 \pm 2.0$ & 100.7 \\
S2 $-\mathrm{S} 3$ & $0.1-10.0$ & 0.999 & 0.232 & 0.4 & 1.3 & $\mathrm{ND}$ & ND \\
\hline
\end{tabular}

${ }^{a}$ Duplicate of sample S1 used in the addition/recovery test; b ${ }^{b} \mathrm{OD}$ limit of detection; ${ }^{\mathrm{L}} \mathrm{OQ}$ limit of quantification; ${ }^{\mathrm{d} C o n c e n t r a t i o n}$ recovered from $833 \mathrm{mg} \mathrm{kg}^{-1}$ addition of sodium chloride to oil sample S1 before EIBE. ND, not-determined.

Performance characteristics (linearity, LOD, LOQ, and recovery percentages) for chloride in sample $\mathrm{S} 1$ were established from the calibration curves. The concentration of the blank sample was $0.30 \pm 0.03$ $\mathrm{mg} \mathrm{kg}^{-1}$. The LOD was calculated as three times the standard deviation (s) of sample blank noise ( $\mathrm{s}=$ $0.03 \mathrm{mg} \mathrm{kg}^{-1}$ ) divided by the slope of the calibration curve (a), i.e. 3s/a, while the LOQ was calculated as 10 times the standard deviation (s) of sample blank noise $\left(\mathrm{s}=0.03 \mathrm{mg} \mathrm{kg}^{-1}\right)$ divided by the slope of 
the calibration curve (a), i.e. 10s/a, as defined by the International Union of Pure and Applied Chemistry (IUPAC). Linearity trends were assessed by the curve determination coefficient $(r)(r \geq 0.99)$.

Recovery percentages $(100.4-100.7 \%)$ were evaluated to verify the accuracy of the EIEB procedure, indicating a good accuracy (recommended range: 80 to 120\%). The obtained concentrations were the result of two equipment determinations (duplicates) and two authentic duplicates (duplicates of the EIEB procedure).

Therefore, after defining the optimal EIEB conditions and performance characteristics, the EIEB process was performed for four oil samples (S1 - S4). Table $V$ presents the chloride results in the aqueous extracts (E1 - E4) using ion chromatography.

Table V. Salinity results obtained $\left(\mathrm{mg} \mathrm{kg}^{-1} \mathrm{NaCl}\right.$ oil) in oil samples (S1 - S4)

\begin{tabular}{lcccc}
\hline Sample & Oil mass $(\mathbf{g})$ & $\begin{array}{c}\text { Aqueous Extract } \\
\text { Mass }(\mathbf{g})\end{array}$ & $\begin{array}{c}\text { Chloride } \\
\left(\mathrm{mg} \mathrm{L}^{-1}\right)^{\mathrm{a}}\end{array}$ & $\begin{array}{c}\mathrm{NaCl} \\
\left(\mathrm{mg} \mathrm{kg}^{-1}\right)\end{array}$ \\
\hline S1 & 3.0464 & 4.5666 & $333.3 \pm 0.8^{\mathrm{b}}$ & $824.6 \pm 1.9^{\mathrm{c}}$ \\
\hline S2 & 3.0489 & 4.8238 & $316.8 \pm 0.5^{\mathrm{b}}$ & $15.7 \pm 2.6^{\mathrm{c}}$ \\
\hline \multirow{2}{*}{ S3 } & 2.9600 & 3.6820 & $6.8 \pm 0.1^{\mathrm{b}}$ & \\
& 3.0045 & 5.3150 & $6.0 \pm 0.9^{\mathrm{b}}$ & $16.8 \pm 3.7^{\mathrm{c}}$ \\
\hline \multirow{2}{*}{ S4 } & 2.9776 & 5.0511 & $6.94 \pm 0.01^{\mathrm{b}}$ & \\
& 2.9262 & 5.1182 & $4.9 \pm 0.1^{\mathrm{b}}$ & $17.3 \pm 2.3^{\mathrm{c}}$ \\
\hline
\end{tabular}

${ }^{a}$ Chloride concentrations in aqueous extracts (E1 - E4) determined in duplicate by the ion chromatograph. ${ }^{b}$ Standard deviation of instrument duplicates. ${ }^{\circ}$ Authentic duplicates of the EIBE procedure.

Samples S2, S3, and S4 presented lower sodium chloride concentrations, although above the LOQ (1.3 $m \mathrm{mg}^{-1}$ ), in the extracts (E2, E3, and E4, respectively), ensuring acceptable accuracy and precision. This control is essential, as the maximum salt content, expressed as the sodium chloride mass (mg) dissolved in $1 \mathrm{~kg}$ of oil is $570 \mathrm{mg} \mathrm{kg}^{-1}$ at the production stage, while refineries establish salt content of below $5 \mathrm{mg}$ $\mathrm{kg}^{-1}[3,9]$. Thus, salinity should be evaluated before refining for all assessed samples S1 - S4. In addition, sample $\mathrm{S} 1$ must undergo desalinization processes ( $\mathrm{NaCl}$ removal) prior to the oil production and refining steps.

\section{CONCLUSIONS}

The screening step using a $2^{2}$ factorial design with three central points allowed for the selection of the significant EIEB variables $\left(\mathrm{HNO}_{3}-\mathrm{V}\right.$ volume and Triton $\mathrm{X}-114$ mass $\left.-\mathrm{T}\right)$ for chloride extraction for the aqueous oil phase. The optimization of variable $\mathrm{V}$ (most significant) was performed in a univariate manner, to obtain the ideal volume of this acid for the EIEB process. High $\mathrm{HNO}_{3}$ concentrations may facilitate chloride extraction into the aqueous phase. However, residual acidity in the aqueous phase may increase conductivity during chloride determination by ion chromatography, causing problems during the analysis. Interaction $(\mathrm{V} / \mathrm{T})$ was not significant for chloride extraction into the aqueous phase. Thus, variables $\mathrm{V}=500$ $\mu \mathrm{L}$ and $\mathrm{T}=0.5000 \mathrm{~g}$ were established for the EIBE process.

The analytical procedure developed for chloride determination in the aqueous oil phase after EIBE displayed adequate precision and accuracy. Adequate linearity $(r>0.99)$, LOD $\left(0.3-0.4 \mathrm{mg} \mathrm{kg}^{-1}\right)$ and LOQ $\left(1.0-1.3 \mathrm{mg} \mathrm{kg}^{-1}\right)$ guaranteed method precision. Accuracy was confirmed by addition/recovery tests $(100.4-100.7 \%)$. All samples displayed salinity values above the ideal maximum concentration for the oil 
refining step $\left(5 \mathrm{mg} \mathrm{kg}^{-1}\right)$. Besides, one of the studied samples presented salinity exceeding the maximum permissible concentration for oil production steps, of $570 \mathrm{mg} \mathrm{kg}^{-1}$. Therefore, as the presence of chloride directly interferes in oil refining and processing, it should be assessed and determined in refineries as a means of obtaining new measures to prevent corrosion processes in the oil industry.

\section{Acknowledgments}

The authors would like to thank the FAPERJ, the Petrobras S.A. Fluid Laboratory and Coordenação de Aperfeiçoamento de Pessoal de Nível Superior - Brasil (CAPES).

\section{REFERENCES}

1. Speight, J. G. Handbook of Oil Product Analysis. Wiley-Interscience, Hoboken, 2002, Chapter 1, p 3.

2. Thomas, J. E. Fundamentos da Engenharia do Petróleo. Interciência, Rio de Janeiro, 2001, pp 4-11.

3. Morigaki, M. K.; Chimin, R. Q. F.; Sad, C. M. S.; Filgueiras, P. R.; Castro, E. V. R.; Dias, J. C. M. Quim. Nova, 2010, 33 (3), pp 607-612 (http://dx.doi.org/10.1590/S0100-40422010000300023).

4. Vieira, L. V.; Rainha, K. P.; Castro, E. V. R.; Filgueiras, P. R.; Carneiro, M. T. W. D.; Brandão, G. P. Microchem. J., 2016, 124, pp 26-30 (https://doi.org/10.1016/j.microc.2015.07.011).

5. Souza, M. O.; da Silva, F. L. F.; Matos, W. O.; Ferreira, R. Q. Rev. Virtual. Quim., 2017, 9 (4), pp 1658-1671 (http://dx.doi.org/10.21577/1984-6835.20170095).

6. Terra, W. S.; Martins, L. L.; da Cruz, G. F. Rev. Virtual. Quim., 2019, 11 (4), pp 1344-1363 (https://doi. org/10.21577/1984-6835.20190093).

7. Souza M. O.; Rainha, K. P.; Castro, E. V. R.; Carneiro, M. T. W. D.; Ferreira, R. Q. Quim. Nova, 2015, 38 (7), pp 980-986 (http://dx.doi.org/10.5935/0100-4042.20150095).

8. Hardaway, C.; Sneddon, J.; Beck, J. N. Anal. Lett., 2004, 37, pp 2881-2899 (https://doi.org/10.1081/ AL-200035776).

9. Souza M. O.; Ribeiro M. A.; Carneiro M. T. W. D.; Athayde G. P. B.; Castro E. V. R.; Silva F. L. F.; Matos W. O.; Ferreira R. Q. Fuel, 2015, 154, pp 181-187 (https://doi.org/10.1016/j.fuel.2015.03.079).

10. Chimin, R. Q. F.; de Castro, E. V. R.; Lima, T. A.; Machado, F. G.; Gomes, A. O.; Guimarães R. C. L.; Malacarne, M. M. Petrol. Sci. Technol., 2016, 34 (8), pp 726-731 (https://doi.org/10.1080/10916466.2 016.1163396).

11. Nelson, J.; Poirier, L.; Linhares, F. L. J. Anal. At. Spectrom., 2019, 34 (7), pp 1433-1438 (https://doi. org/10.1039/C9JA00096H).

12. Barroso-Solares, S.; Pinto, J.; Nanni, G.; Fragouli, D.; Athanassiou, A. RSC Adv., 2018, 8 (14), pp 7641-7650 (https://doi.org/10.1039/C7RA12646H).

13. Trevelin, A. M.; Marotto, R. E. S.; Castro, E. V. R.; Brandão, G. P.; Cassela, R. J.; Carneiro, M. T. W. D. Microchem. J., 2016, 124, pp 338-343 (https://doi.org/10.1016/j.microc.2015.09.014).

14. ASTM D 6470, Standard test methods for salt in crude oils (potentiometric method). West Conshohocken, PA: ASTM International, 2004.

15. ASTM D3230-19, Standard Test Method for Salts in Crude Oil (Electrometric Method), ASTM International, West Conshohocken, PA, 2019.

16. Robaina, N. F.; Feiteira, F. N.; Cassella, A. R.; Cassella, R. J. J. Chromatogr. A, 2016, 1458, pp 112117 (https://doi.org/10.1016/j.chroma.2016.06.066).

17. Neto, B. B.; Scarminio, I. S.; Bruns, R. E. Como fazer experimentos. Bookman: São Paulo, 2010, Chapter 1, pp 15-19.

18. Souza, R. M.; Saraceno, A. L.; Silveira, C. L. P.; Aucelio, R. Q. J. Anal. At. Spectrom., 2006, 21 (11), pp 1345-1349 (https://doi.org/10.1039/B605643C).

19. Duyck, C.; Miekeley, N.; Silveira, C. L. P.; Aucélio, R. Q.; Campos, R. C.; Grinberg, P.; Brandão, G. P. Spectrochim. Acta. B., 2007, 62 (9), pp 939-95. (https://doi.org/10.1016/j.sab.2007.04.013).

20. Souza, R. M.; Meliande, A. L. S.; Silveira, C. L. P.; Aucélio, R. Q. Microchem. J., 2006, 82 (2), pp 137-141 (https://doi.org/10.1016/j.microc.2006.01.005). 